\title{
Turismo e Mobilidade: um diagnóstico da acessibilidade geográfica à fronteira Chuí-Rio Grande do Sul/RS, Brasil/Chuy, Uruguai
}

\section{Tourism and Mobility: a diagnosis about geographic acessibility to border Chuí- Rio Grande do Sul/RS, Brasil/Chuy, Uruguai}

\author{
Jaciel Gustavo Kunz (KUNZ, J. G.) ${ }^{*}$ e \\ Eline Tosta (TOSTA, E.) ${ }^{* *}$
}

\begin{abstract}
RESUMO - O tema "mobilidade turística", cujo debate ainda é incipiente no Brasil, transcende a ideia do deslocamento tendo o turismo como finalidade. O objetivo deste trabalho foi o de diagnosticar a acessibilidade geográfica da fronteira Chuí/ Rio Grande do Sul, Brasil - Chuy/Uruguai a partir da análise dos principais fluxos do transporte aéreo dos aeroportos de Pelotas/RS/Brasil, Porto Alegre//RS/Brasil e Montevidéu/Uruguai e levantamento da oferta de acesso por meio do transporte coletivo rodoviário. Foram consultados diariamente os voos dos aeroportos no período de 7 dias ininterruptos e páginas web de empresas de ônibus que operavam linhas regulares até a fronteira. Pôde-se observar que a acessibilidade estava relacionada a outros fatores senão à (in)disponibilidade de transporte e que para compreender a mobilidade é necessário considerar fatores políticos e estratégias econômicas e corporativas. Sugerese para estudos futuros relacionar como a acessibilidade local e a micro acessibilidade implicam no turismo emissivo e receptivo nas áreas de fronteira.
\end{abstract}

Palavras-chave: Turismo; Mobilidade territorial; Acessibilidade geográfica; Fronteiras. Chuí/Brasil-Chuy/Uruguai.

ABSTRACT - The theme "tourist mobility", which the debate is still incipient in Brazil, transcends the idea of displacement having tourism as purpose. The goal of this research is to diagnose the geographical accessibility to border Chui / Brazil - Chuy / Uruguay from the analysis from the main flows of air transport from the airports of Pelotas / RS, Porto Alegre / RS and Montevideo / Uruguay and to survey acess supply by the road public transport. It were consulted flights from the airports sites daily, within 7 days uninterruptedly, and from companies which operate regular routes to the border's web pages. It may be noted that accessibility is related to factors other than the (un) availability of transport and, in addition, that in order to understand the mobility it's necessary to consider policy factors and also corporate and economic strategies. It is

\footnotetext{
* Formação: Graduação em Turismo pela Pontifícia Universidade Católica do Rio Grande do Sul (PUCRS), Mestrado em Turismo pela Universidade Caxias do Sul (UCS) e Doutorando em Geografia pela Universidade Federal do Rio Grande do Sul (UFRGS). Atividade profissional: Docente no Curso de Turismo Binacional da Universidade Federal de Rio Grande (FURG). Coordenador do Projeto de Pesquisa "Mobilidade turística na fronteira Chuí-Brasil/Chuy-Uruguai". Endereço físico para correspondência: Universidade Federal do Rio Grande - Campus Santa Vitória do Palmar. Rua Glicério P. de Carvalho, 81, Bairro Coxilha. CEP 96230-000 - Santa Vitória do Palmar/RS - Brasil. E-mail: jacielkunz@gmail.com

** Formação: Bacharelado em Turismo Binacional do Campus Avançado da Universidade Federal do Rio Grande (FURG), localizado no município de Santa Vitória do Palmar. Bolsista do Projeto de Pesquisa "Mobilidade turística na fronteira Chuí-Brasil/Chuy-Uruguai". Endereço físico para correspondência: Universidade Federal do Rio Grande - Campus Santa Vitória do Palmar. Rua Glicério P. de Carvalho, n. 81, Bairro Coxilha. CEP 96230-000 - Santa Vitória do Palmar/RS - Brasil. E-mail: elinefurg@ gmail.com
} 
suggested for future studies to approch the means by which local and micro emissive and receptive tourism in the border areas.

Key words: Tourism; Territorial mobility; Geographical accessibility; Borders; Chuí/Brasil -Chuy/Uruguai. 


\section{INTRODUÇÃO}

O avanço da tecnologia em comunicação e transportes, da globalização dele resultante, contribuiu com a noção de tempo e espaço contraído e, consequentemente, o desenvolvimento da mobilidade. Quanto maior a disponibilidade de infraestrutura (transporte público, espaços de circulação), a interligação destes à acessibilidade em transporte (rápido e eficiente), maior será a mobilidade das pessoas, informações e bens (ALLIS, 2010; CASTRO; LOHMANN, 2013).

Santos e Silveira (2004, p. 140) afirmam que os equipamentos coletivos, construídos com recursos públicos, tendem a priorizar empresas hegemônicas, e, por isso acabam aprofundando "o uso seletivo do território, deixando excluída ou depreciada a maior parte da economia e da população". Dessa forma, criam-se regiões periféricas devido, entre outros fatores, à indisponibilidade e falta de interligação de modais de transporte, que comprometem a difusão da globalização e desenvolvimento econômico em alguns lugares.

Para Osório (1998), as desigualdades e exclusões advindas do processo de globalização - quais sejam, tecnológicas, econômicas, sociais - vêm sendo reforçadas, em diferentes escalas, fazendo com que fronteiras (re)surjam, tornando necessário, portanto, repensar essas regiões.

Os municípios Chuí (Rio Grande do Sul/Brasil) e Chuy (Rocha/Uruguai) são cidades gêmeas, ou seja, se caracterizam pela integração urbana e funcional entre cidades de países vizinhos. Chuí/RS possui cerca de 5.917 habitantes (IBGE, 2014). O município de Chuy, por sua vez, possui cerca de 9.675 habitantes (URUGUAY, 2014). O acesso a ambas cidades se dá através da rodovia brasileira BR-471 e das Ruta 19 e Ruta 9 pelo Uruguai.

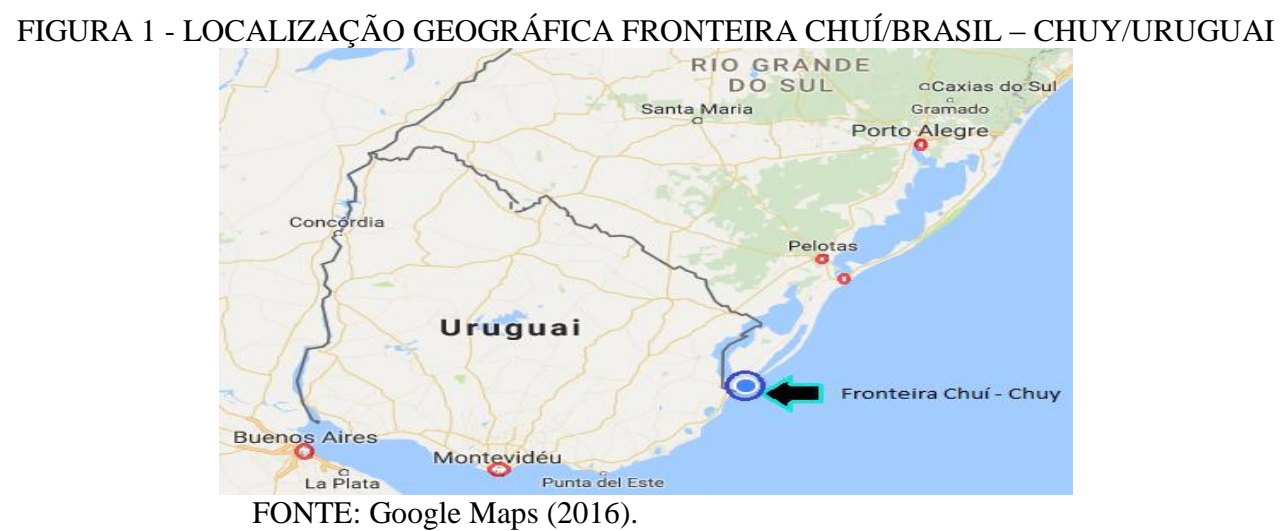


Verificou-se que o modal de transporte mais rápido que garante acesso até a faixa de fronteira é o rodoviário. O deslocamento por via aérea, objeto de estudo deste trabalho, é dificultado pelo fato de os principais aeroportos estarem distantes da fronteira Chuí/Chuy. Os mais próximos estão nas cidades brasileiras de Pelotas (260 $\mathrm{km})$ e Porto Alegre $(520 \mathrm{~km})$ e nas cidades uruguaias Punta Del Este $(220 \mathrm{~km})$ e Montevidéu (325 km), cabendo, nesse caso, considerar-se a intermodalidade ${ }^{1}$.

Sendo assim, buscou-se diagnosticar a acessibilidade geográfica da fronteira Chuí/Brasil - Chuy/Uruguai a partir da análise dos principais fluxos do transporte aéreo dos aeroportos de Pelotas/RS, Porto Alegre/RS e Montevidéu/Uruguai, os mais próximos ao objeto de análise, que estavam oferecendo linhas aéreas regularmente. Além disso, através de levantamento do transporte coletivo rodoviário, procurou-se compreender a conexão da fronteira com os principais aeroportos da região. Optou-se por não abordar a automobilidade (a realização da mobilidade por meio do automóvel) por considerá-la como um modelo complexo, cabendo um estudo à parte.

\section{REFERENCIAL TEÓRICO}

Tendo apresentado o escopo temático deste trabalho, cabe discutir os conceitos e temas a ele subjacentes, divididos do seguinte modo: i) mobilidade territorial e acessibilidade geográfica aos destinos turísticos; ii) fronteiras, mobilidade e turismo; e, iii) comentários sobre a trajetória e as características das companhias aéreas pioneiras no Brasil e no Uruguai.

\subsection{MOBILIDADE TERRITORIAL E ACESSIBILIDADE GEOGRÁFICA AOS DESTINOS TURÍSTICOS}

O desenvolvimento do transporte aéreo beneficiou diversas atividades humanas, desencadeando uma grande mobilidade e rompendo fronteiras até então consideradas instransponíveis (BENI, 2007), passando a ser um importante vetor de conexão territorial e promoção das interações espaciais (PEREIRA, 2011).

\footnotetext{
${ }^{1}$ Informações de distâncias conforme página web <http://distanciacidades.com/>. Acesso em 1 mar.2017.
} 
Castro e Lohmann (2013) observam que nenhuma outra tecnologia de transportes foi tão fundamental quanto as do modal aéreo, pois o avião provê o deslocamento seguro e mais rápido e a um menor custo, atendendo aos ditames do modo capitalista de produção. Barat (2010) também destaca o transporte aéreo como fator de suporte à globalização, já que promove o grande crescimento da escala de movimentação de pessoas e de cargas. Pereira (2011), por sua vez, afirma que o transporte aéreo se caracteriza como um modal da (pós) modernidade, pois opera na brevidade espaço-tempo, o que maximiza sua funcionalidade.

Além disso, o transporte aéreo se revela como um meio para a manutenção pelo qual a sociedade mantém suas relações sociais e econômicas. Por intermédio do aumento da conectividade proporcionada por este modal, o processo de reprodução do capital e o desenvolvimento econômico são acelerados e potencializados (LIPOVICH, 2006; PEREIRA, 2011).

Tal conectividade pode ser observada em distintos graus de acordo com a centralização espacial dos fluxos. Casos por meio dos quais se verificam núcleos de máxima hierarquia são denominados $h u b s^{2}$. Tais núcleos são formados a fim de diminuir os custos empresariais e operacionais, favorecer alianças ou acordos comerciais e incrementar a conectividade das cidades (LIPOVICH, 2006), reconfigurando as redes, e estabelecendo-se nós.

Castells (1999) considera que uma rede é um conjunto de nós interconectados. Os nós das redes técnicas, por sua vez, são configurados a partir da "atratividade, de seu potencial de acessibilidade e sua conectividade, de sua infraestrutura adequada e de sua densidade técnica" (PEREIRA, 2011, p. 478).

Entretanto, as redes e os sistemas de transporte não ocorrem de maneira homogênea no território, podendo provocar tanto a integração quanto a fragmentação do espaço. A integração e a fluidez de alguns territórios correspondem à fragmentação ou imobilidade de outros (PEREIRA; SILVEIRA 2009), que passam a ficar às margens do processo de globalização.

Sendo assim, uma rede viabiliza o reforço à interdependência entre os lugares, mas também contribui para as desigualdades territoriais, por constituir-se hierarquicamente, estabelecendo, assim, uma relação de inclusão-exclusão (SILVEIRA,

\footnotetext{
${ }^{2}$ Pontos nodais de uma complexa e densa rede global de transporte aéreo, tanto de turistas, quanto de mercadorias (KUNZ, 2014).
} 
2003; BECKER, 2006). Por tal motivo, as redes revelam "relações marcadas pelo poder" (RAFFESTIN, 1993, p. 2) e são responsáveis por redefinirem, em nível global, o território, possibilitando novos e acelerados fluxos materiais (PEREIRA; SILVEIRA, 2009) e imateriais. Dentre os fluxos físicos/materiais estão os de pessoas/turistas, que, por sua vez, estão condicionados em muitos casos à integração dos modais transportes, a qual possibilita mais opções de acessibilidade de/para o destino final (PALHARES, 2002).

\subsection{FRONTEIRAS, MOBILIDADE E TURISMO}

Para Coriolano e Fernandes (2012, p. 1) mobilidade "significa facilidade para se mover, para ser movido". Tal facilidade depende da acessibilidade, que consiste na "facilidade em atingir os destinos desejados" (COCCO, 2011, p. 613-614). Para Beni (2011, p. 29), a globalização foi responsável por promover "uma maior disponibilização e acessibilidade em amplitude mundial dos produtos, das instalações e dos serviços turísticos". Porém, como já dito anteriormente, tal disponibilização acontece de modo seletivo no território, contribuindo com o surgimento de regiões periféricas carentes de interligação de modais de transporte, como é o caso das fronteiras.

Beni (2011, p. 179) salienta, em termos de transporte turístico, que "a organização do turismo intrarregional continua excessivamente vinculada ao intercâmbio aéreo entre grandes capitais e não favorece a relação transfronteiriça". O mesmo autor destaca, ainda, que os turistas que fazem percursos até lugares periféricos, como as fronteiras, têm a necessidade de voltar à capital para embarcar em um voo internacional. Sendo assim, uma região fronteiriça pode apresentar obstáculos à mobilidade do capital, de mercadorias e pessoas, incluindo os turistas (HISSA, 2002). Beni (2011) aponta que nos casos de voos fronteiriços, acontece o aumento do custo e do tempo das viagens. Dessa forma, pode-se considerar que obstáculos são criados devido às restrições geográficas que, por sua vez, comprometem a acessibilidade e a mobilidade.

Cohen e Cohen (2012) ressaltam, ainda, que as fronteiras são complexificadas pelo dualismo do nacional e do internacional. O caso da compra na fronteira, pode ser citado como um exemplo dessa complexidade, pois está historicamente vinculado à 
competitividade de preços mais baixos do lado estrangeiro, de acordo com o momento político e econômico vivido de cada lado (BENTO, 2012; ALLIS; PAULA; RASZL, 2015). Castrogiovanni (2012, p. 37) afirma que "no caso da fronteira entre Brasil e Uruguai [por exemplo] a atratividade parece estar cada vez mais relacionada à oferta trazida pelos free shops e à diferença cambial”. Esse parece ser o caso da fronteira ChuíChuy em que é possível verificar essa variação de fluxo de pessoas conforme a variação cambial.

\subsection{COMENTÁRIOS SOBRE A TRAJETÓRIA E AS CARACTERÍSTICAS DAS COMPANHIAS AÉRAS PIONEIRAS}

O primeiro voo do Uruguai aconteceu em 26 de agosto de 1910 e foi realizado pelo piloto Enrique Martínez Velazco em uma aeronave de fabricação nacional (MARURI, 2010). Em 1º de dezembro de 1912 Pablo Teodoro Fels realizou a primeira travessia aérea entre Buenos Aires e Montevidéu (MARURI, 2010). Tal fato incentivou o nascimento da aviação Uruguaia, pois:

[...] a chegada desse homem motivou o verdadeiro nascimento do ministério da Guerra e Marinha. O general Juán Vernaza y Jerez, contratou, em Buenos Aires, Marcel Paillet, um piloto francês que tinha dado instrução na Escola de Aviação Militar da Argentina. Paralelamente a isso, em dezembro de 1912 também começou o nascimento da aviação civil, com a criação do Comitê Nacional de Aviação, que logo se transformou no Aeroclube do Uruguai que ainda existe (MARURI, 2010, s. p., tradução nossa).

Segundo Castillo e Monteverde (2011), em 20 de novembro de 1936 a empresa Pluna realizou o primeiro voo civil do país, com o trecho Montevidéu - Salto Montevidéu. Os aviões eram biplanos, bimotores e tinham capacidade para dois pilotos e apenas três passageiros. Depois de período entre nacionalização (1951) e privatização (1995) declarou falência em 2012, o que tornou favorável o investimento de companhias estrangeiras a atuarem no país (CASTILLO; MONTEVERDE, 2011).

De acordo com Gastal (2009), no Rio Grande do Sul, Brasil, a aviação comercial começou em 1927 a partir da fundação da Sociedade Anônima Empresa de Viação Aérea Rio Grandense (Varig), do alemão naturalizado brasileiro Otto Ernesto Meyer. A 
empresa adquiriu na Alemanha o hidroavião Atlântico e obteve licença para voos regulares em território brasileiro. No dia 27 de janeiro de 1927:

[...] o Atlântico levantou voo da Baía de Guanabara, às 9h30min, e, depois de escala em Santos, São Francisco e Florianópolis, pousou nas águas tranquilas do Guaíba, às $12 \mathrm{~h} 30 \mathrm{~min}$, sendo recebido triunfalmente. A 3 de fevereiro, voltou a alçar voo, desta feita em direção a Rio Grande, numa viagem de estudos. [...] A bordo viajaram os srs. Guilherme Gastal e João Oliveira Goulart que, tendo pago as suas passagens, tornaram-se os primeiros passageiros da aviação comercial brasileira (FLORES, 1993, p. 20).

Conforme Gastal (2009), no mesmo ano a Varig começou a operar serviços regulares de passageiros e cargas entre as cidades de Porto Alegre, Pelotas e Rio Grande. Foi dessa forma que o "percurso da Varig acompanhou, em muitos momentos, a construção do Turismo no Brasil”' (GASTAL, 2009, p. 187).

Após um longo período desfavorável, aliado a fatores internos como (modelo de gestão da empresa) e externos - tais como guerras, clima, abertura do mercado, elevado preço dos combustíveis - a empresa declarou falência e encerrou suas atividades em 2006 (HELMS, 2010).

\section{ASPECTOS METODOLÓGICOS}

A presente pesquisa trata-se de um estudo de caso, e pode ser caracterizada quanto aos objetivos como exploratória. Quanto aos procedimentos técnicos é entendida como documental e quanto à abordagem, caracteriza-se como quali-quantitativa.

Para a elaboração deste trabalho foram consultados diariamente os voos dos aeroportos de Pelotas/RS e Porto Alegre/RS no período de 20 de janeiro de 2015 a 26 de janeiro de 2015, disponíveis no site 〈http://www4.infraero.gov.br> da Empresa Brasileira de Infraestrutura Aeroportuária (INFRAERO, 2015). Também foram consultados os voos do aeroporto de Montevidéu, consultados diariamente, no mesmo período, no site do próprio aeroporto, <http://www.aeropuertodecarrasco.com.uy/>, caracterizando coleta de dados secundários (pesquisa documental). Desconsiderou-se os voos com chegada ao aeroporto de Punta Del Este, pois o mesmo não apresentou no 
período voos regulares diariamente, conforme consulta à página web <http://www.puntadeleste.aero/>.

A coleta dos dados de tarifas, disponibilidade e duração da viagem se deu a partir da simulação dos mesmos voos entre o período 21 a 28 de janeiro de 2015 (7 dias) na página web das empresas aéreas ${ }^{3}$, com o intervalo de 3 semanas da viagem, desconsiderando o período do feriado de Carnaval, caracterizado por alta procura e sazonalidade de oferta de voos e provável aumento das tarifas normalmente praticadas. Nessa coleta foram pesquisados somente voos diretos (trechos únicos) tendo as cidades de Porto Alegre/RS, Pelotas/RS e Montevidéu como destinos ${ }^{4}$.

Em relação aos dados do transporte coletivo rodoviário, as pesquisas foram realizadas através de simulações de compra na página web das empresas brasileiras Planalto e Embaixador e uruguaias TTL, Expreso Chago, Cot, Cynsa, Rutas del Sol e Ega, que estavam oferecendo os serviços, no período de 25 de setembro de 2014 a $1^{\circ}$ de outubro de $2014^{5}$. Em caso de informações não disponibilizadas via internet, recorreuse ao guichê de vendas das rodoviárias para dados relacionados ao tempo de paradas, serviços e preços.

\section{RESULTADOS}

Nesta seção, apresentam-se e analisam-se os resultados da pesquisa. A seção está subdividida em: i) diagnóstico da oferta e de transporte aéreo de Porto Alegre, Montevidéu e Pelotas; e, ii) diagnóstico da oferta rodoviária/transporte coletivo desde os municípios de Chuí-Rio Grande do Sul/RS, Brasil/Chuy, Uruguai.

\footnotetext{
${ }^{3}$ Gol, Tam, Azul, Avianca, Austral, Tap, Taca, Copa, Amaszonas, Iberia, Lan, BQB, Air France e American Airlines.

${ }^{4}$ Tendo como fonte as páginas do aeroporto de Porto Alegre <http://www.aeroportoportoalegre.net/>; Pelotas <http://www4.infraero.gov.br/aeroportos/aeroporto-internacional-de-pelotas-rs-joao-simoeslopes-neto/voos-online/> e Montevideu <http://www.aeropuertodecarrasco.com.uy/>.

${ }^{5}$ Tendo como fontes a página web da empresa TTL <http://www.ttl.com.br/produtos-e-servicos/precoshorarios/>; Expresso Chago e Cynsa <http://www.trescruces.com.uy>, Rutas del Sol $\langle$ http://www.rutasdelsol.com.uy/tarifas.php>, Cot <http://www.cot.com.uy/site> e Ega $<$ http://www.ega.com.uy/horarios_tarifas.php>.
} 


\subsection{DIAGNÓSTICO DA OFERTA DE TRANSPORTE AÉREO: PORTO ALEGRE, MONTEVIDÉU E PELOTAS}

Analisando os voos que chegavam a Porto Alegre, verificou-se que a principal vinculação aérea desta estava sendo com a cidade de São Paulo ${ }^{6}$, um hub nacional, tendo apresentado 249 voos para o período analisado de apenas sete dias, conforme Tabela 1.

TABELA 1 - OFERTA DE VOOS E DESTINOS (PORTO ALEGRE/RS)

\begin{tabular}{|c|c|c|c|c|c|c|c|}
\hline \multirow[b]{2}{*}{ Origem } & \multirow[b]{2}{*}{ Alcance $^{7}$} & \multirow{2}{*}{$\begin{array}{c}\text { Companhia } \\
\text { aérea }\end{array}$} & \multicolumn{2}{|c|}{ Frequências } & \multirow{2}{*}{$\begin{array}{c}\text { Média } \\
\text { Preço } \\
\text { (R\$) }\end{array}$} & \multirow{2}{*}{$\begin{array}{c}\text { Duração } \\
\text { a partir } \\
\text { de }(h)\end{array}$} & \multirow{2}{*}{$\begin{array}{c}\text { Distância } \\
\text { Terrestre } \\
\text { (km) }\end{array}$} \\
\hline & & & $\begin{array}{l}\text { Média } \\
\text { Diária }\end{array}$ & $\begin{array}{c}\text { Voos } \\
\text { semanais }\end{array}$ & & & \\
\hline São Paulo - SP & $\mathrm{N}$ & $\begin{array}{c}\text { Avianca } \\
\text { Azul } \\
\text { Gol } \\
\text { Tam }\end{array}$ & 35,7 & 249 & 196,12 & $1: 22$ & 1143 \\
\hline Rio de Janeiro - RJ & $\mathrm{N}$ & $\begin{array}{c}\text { Azul } \\
\text { Gol } \\
\text { Tam }\end{array}$ & 11 & 77 & 492,71 & 2 & 1570 \\
\hline Florianópolis - SC & $\mathrm{N}$ & $\begin{array}{l}\text { Azul } \\
\text { Gol }\end{array}$ & 5,57 & 39 & 472,22 & 1 & 456 \\
\hline Campinas - SP & $\mathrm{N}$ & Azul & 4,85 & 34 & 222,66 & $1: 40$ & 1201 \\
\hline Brasília - DF & $\mathrm{N}$ & $\begin{array}{l}\text { Gol } \\
\text { Tam }\end{array}$ & 4,71 & 33 & 832,68 & $2: 40$ & 2113 \\
\hline Buenos Aires & I & $\begin{array}{c}\text { Austral } \\
\text { Gol }\end{array}$ & 3,42 & 24 & 1063,27 & $1: 35$ & 843 \\
\hline Belo Horizonte - MG & $\mathrm{N}$ & $\begin{array}{l}\text { Azul } \\
\text { Gol }\end{array}$ & 2,71 & 19 & 260,61 & $2: 25$ & 1726 \\
\hline Foz do Iguaçu - PR & $\mathrm{N}$ & $\begin{array}{l}\text { Azul } \\
\text { Gol }\end{array}$ & 2,14 & 15 & 172,90 & $1: 50$ & 906 \\
\hline Curitiba - PR & $\mathrm{N}$ & $\begin{array}{l}\text { Azul } \\
\text { Tam }\end{array}$ & 1,85 & 13 & 145,23 & $0: 50$ & 741 \\
\hline Salvador - BA & $\mathrm{N}$ & Gol & 1 & 7 & 490,00 & $3: 55$ & 3129 \\
\hline Lima & I & Taca & 1 & 7 & 2885,00 & $4: 40$ & 3332 \\
\hline Cidade do Panamá & I & Copa & 1 & 7 & 2275,74 & $7: 10$ & 5295 \\
\hline Pelotas - RS & $\mathrm{N}$ & Azul & 1 & 7 & 146,47 & $0: 55$ & 220 \\
\hline Santa Maria - RS & $\mathrm{N}$ & Azul & 1 & 7 & 100,6 & $0: 40$ & 253 \\
\hline
\end{tabular}

\footnotetext{
${ }^{6}$ Referente aos aeroportos Congonhas e Guarulhos.

7 "N" refere-se a voo de alcance nacional e "I" refere-se a voo de alcance internacional.

${ }^{8}$ Dados obtidos a partir de consulta na página web distanciacidades.com.
} 


\begin{tabular}{l|c|c|c|c|c|c|r} 
Passo Fundo - RS & N & Azul & 0,85 & 6 & - & - & - \\
Recife - PE & N & Gol & 0,85 & 6 & - & - & 3803 \\
Lisboa & $\mathrm{I}$ & Tap & 0,57 & 4 & 2052,00 & 12 & 8811 \\
Montevidéu & $\mathrm{I}$ & Gol & 0,57 & 4 & 1159,00 & $1: 11$ & 713 \\
Londrina - PR & $\mathrm{N}$ & Azul & 0,42 & 3 & 195,00 & 2 & 749 \\
Maceió - AL & $\mathrm{N}$ & Gol & 0,28 & 2 & - & - & 3572 \\
Fortaleza - CE & $\mathrm{N}$ & Gol & 0,14 & 1 & - & - & 4100 \\
Chapecó - SC & $\mathrm{N}$ & Azul & 0,14 & 1 & 699,00 & $1: 05$ & 354 \\
Natal - RN & $\mathrm{N}$ & Gol & 0,14 & 1 & - & - & 4084 \\
\hline
\end{tabular}

FONTE: Elaboração própria dos autores (2015), com base em informações dos sites das companhias aéreas.

Pôde-se observar que os voos para a cidade de São Paulo representaram 43,5\% da movimentação de passageiros do aeroporto Salgado Filho (Porto Alegre). A capital paulista se caracteriza por ser uma megalópole e centro de comando do território nacional. Também se pôde perceber o destino como o de maior diversidade de companhias aéreas, característica de destino com centralidade e tendência à centralização. Pôde-se notar também que a vinculação aérea de Porto Alegre com São Paulo estava sendo 2,73 vezes maior que com os aeroportos da região Sul.

A oferta de voos com origem no Rio de Janeiro representou 13,5\% do total. A capital fluminense, juntamente de São Paulo e Brasília, é um dos três centros de gestão do território nacional situados no nível superior da hierarquia da rede urbana brasileira, segundo estudo do $\operatorname{IBGE}^{10}$ (2007). Além disso, a cidade é um importante destino turístico: ao lado de São Paulo e Porto Alegre, o Rio de Janeiro era um dos três municípios a alcançar o estrato máximo da competitividade turística no Brasil (nível 5), de acordo com relatório publicado pelo Ministério do Turismo (2015) ${ }^{11}$, em parceria com a Fundação Getúlio Vargas - FGV e o Serviço de Apoio às Micro e Pequenas Empresas - Sebrae (Nacional).

Sendo assim, verificou-se que $57 \%$ do total de voos que chegava em Porto Alegre tinha origem em São Paulo e Rio de Janeiro. Isso se deve à alta demanda emissiva e receptiva desses destinos e seu entorno e ao fato de serem hubs de conexões

\footnotetext{
${ }^{9}$ Dados referentes ao Aeroporto Internacional de Natal (São Gonçalo do Amarante).

${ }^{10}$ Disponível em: <http://biblioteca.ibge.gov.br/visualizacao/livros/liv40677.pdf>. Acesso em: 06/03/2016.

${ }^{11}$ Disponível em: <http://www.turismo.gov.br/sites/default/turismo/o_ministerio/publicacoes/downloads_ publicacoes/Relatorio_Brasil_2015_WEB.pdf>. Acesso em: 06/03/2016.
} 
para o Brasil e a América do Sul, segundo os sites das concessionárias dos aeroportos internacionais dessas cidades, quais sejam, Guarulhos $^{12}$ e Galeão ${ }^{13}$.

Além disso, de acordo com o índice de cidades globais, consultado no site do Instituto de Estudos Avançados - IEA, São Paulo e Rio de Janeiro são as cidades brasileiras que melhor se posicionam no ranking, embora ainda ocupem posições características das cidades de países periféricos: ocupavam, em 2016, a $34^{\mathrm{a}}$ e a $50^{\mathrm{a}}$ posições (IEA, 2016). Sendo assim, pode-se afirmar que, visto a partir do transporte aéreo de passageiros, a interação de Porto Alegre com o país indicou a forte dependência das cidades de São Paulo e do Rio de Janeiro.

Florianópolis é a capital do estado vizinho de Santa Catarina, sendo a mais próxima de Porto Alegre. No período pesquisado, representou 6,9\% da demanda receptiva/emissiva de voos de Porto Alegre. O estado catarinense era, em 2012, o que mais recebia turistas com origem no RS e que se deslocavam para fora do estado gaúcho, segundo relatório da Fundação Instituto de Pesquisas Econômicas - FIPE (2012). Além disso, caracterizava-se por ser um destino sazonal: no ano de 2015, somente nos meses de dezembro, janeiro e fevereiro, a cidade recebeu quase $3 / 4$ do montante anual $(74,36 \%)$ de turistas estrangeiros, considerando-se todos os modais de transporte.

$\mathrm{Na}$ imediatamente inferior apareceu Campinas/SP com 34 voos diretos semanais, frequência muito próxima da oferta da capital federal, Brasília, com 33 voos. A cidade paulista é principal hub da companhia Azul, conforme consultado em seu mapa de $\operatorname{rotas}^{14}$. Já no que se refere a Brasília, Pereira (2014, p. 244) afirma que seu aeroporto "[...] constituiu-se por receber e distribuir um significativo número de voos pelo território nacional, e ser escala/conexão de vários voos [...]”. A autora destaca, ainda, que o aeroporto é objeto das estratégias de concorrência e competitividade das companhias Gol e da então companhia aérea Tam ${ }^{15}$ (PEREIRA, 2014).

\footnotetext{
12 Disponível em: <https://www.gru.com.br/pt/institucional/sobre-gru-airport/historico>. Acesso em: 06/03/2017.

13 Disponível em: <http://www.riogaleao.com:81/wp-content/uploads/2016/11/PUB_Presentation2016_ 18-tela.pdf $>$. Acesso em: 06/03/2017.

${ }^{14}$ Disponível em: <http://www.voeazul.com.br/conheca-a-azul/mapa-rotas〉. Acesso em: 06/03/ 2017.

15 A companhia Tam completou seu processo de fusão com a empresa Lan em 2016, passando a ser chamada "Latam", com base na página web <www.latam.com>. Acesso em: 09/09/ 2016.
} 
Buenos Aires ${ }^{16}$, uma metrópole da América Latina e do Mercosul, caracterizavase por ser portão de entrada e saída da Argentina e um ponto de conexão para o Chile, por exemplo, de acordo com pesquisas recentes da FIPE (2015). Pôde-se observar preços elevados devido à temporada de verão.

Para a capital de Minas Gerais, Belo Horizonte, uma das metrópoles mais importantes do país, constatou-se a manutenção de voos diretos, assim como para Foz do Iguaçu/PR, que, por sua vez, é um destino turístico, situado no Oeste do Estado do Paraná, que atrai muitos turistas, inclusive estrangeiros: se posicionando como o terceiro município que mais recebe turistas estrangeiros a lazer no Brasil (FIPE, 2015). Situa-se, além disso, em região de fronteira (Argentina e Paraguai).

Curitiba, considerada uma metrópole regional, apresentou 13 voos na semana. Considerou-se que esse dado poderia significar que houvesse influência da venda de passagens com escala em Curitiba e, portanto, ter baixa oferta de voos diretos, que, porém, não atendiam aos critérios da pesquisa.

Na sequência situou-se a cidade de Salvador, um destino com oferta sazonal, característico da alta temporada, mas que estava oferecendo voos não fretados, tendo um voo por dia no período (verão) abordado. Verificou-se que a capital do Peru, Lima, mantinha a mesma frequência e também poderia ser considerada uma destinação de alta temporada, porém, menos evidente que Salvador. A capital do Peru, além de importante destino turístico na América Latina, $h u b$ da companhia aérea Avianca-Taca, responsável por ligações para a América Central, assim como a Cidade do Panamá, onde se situa o que a companhia Copa denomina "centro de conexões das Américas" (COPA, 2017, s. p.). A capital do Panamá é relevante por suas ligações diretas para a América do Sul, do Norte e Central, além do Caribe, também de acordo com a Copa (2017).

Pelotas, Santa Maria e Passo Fundo, cidades médias do estado do Rio Grande do Sul equidistantes, apresentaram a semelhança de terem voos operados pela companhia Azul, que estava utilizando aeronaves menores nesses trajetos e conectavam essas cidades de importâncias regionais até a capital Porto Alegre. Observou-se que Pelotas e Santa Maria estavam tendo frequência de sete voos semanais, e Passo Fundo tendo seis.

Não se verificou a oferta de voos entre Porto Alegre e Caxias do Sul/RS, pois a mesma localiza-se a $130 \mathrm{~km}$ de distância da capital gaúcha, o que é um fator que

\footnotetext{
${ }^{16}$ Referente aos aeroportos Ezeiza e Aeroparque.
} 
inviabiliza o trajeto, pois, conforme Palhares (2002), por ser um modal de transporte que despende maiores custos, não considera-se adequado para rotas aéreas com menos de 500 km de distância.

As cidades de Recife, com seis voos na semana, assim como Maceió, com dois voos semanais, Fortaleza e Natal, ambas com um voo por semana cada, representaram a demanda pelo litoral do Nordeste, característico, sobretudo, do verão. Tais voos, entretanto, não foram encontrados nos sites de companhia aéreas, o que fez supor que foram voos fretados por operadoras de turismo (charters).

Lisboa, por sua vez, estava sendo o único destino intercontinental operado sem escala até Porto Alegre. A capital portuguesa é o hub da Tap, "plataforma privilegiada de acesso na Europa, na encruzilhada entre o continente Africano e a América do Norte e do Sul" (TAP, 2017, s. p.).

No presente estudo, percebeu-se que Montevidéu, a capital estrangeira mais próxima de Porto Alegre, estava possuindo apenas dois voos semanais, mesmo na alta temporada de fluxo emissivo e receptivo de turistas. Além disso, verificou-se que os preços eram elevados em relação à distância e ao tempo de voo, o que poderia impulsionar a escolha pelo modal rodoviário - coletivo ou próprio.

Londrina/PR, por sua vez, apresentou baixa oferta de voos diretos para Porto Alegre (três por semana) apesar de ser capital regional B (segundo maior estrato dentre as capitais regionais), dentro dos critérios do IBGE (2007). Assim como Londrina, Chapecó, município próximo à divisa de SC com o norte do RS e sudoeste do PR, é um centro regional, entretanto, verificou-se preço elevado em relação à distância terrestre de $354 \mathrm{~km}$ até Porto Alegre.

Pôde-se verificar a relevância da companhia aérea Azul nos voos diretos com capitais regionais, pontos estratégicos de contato dos grandes centros com o meio rural e a fronteira. Entre as capitais regionais/cidades médias e/ou não capitais que contavam com ligação direta com Porto Alegre estavam: Campinas, Foz do Iguaçu, Pelotas, Santa Maria, Passo Fundo, Londrina e Chapecó.

Pode-se afirmar, conforme Santos e Silveira (2004), que o "moderno" não é difundido igualmente no território, nesse caso, as fronteiras - com exceção de Foz do Iguaçu - tendo uma pequena participação na circulação e nos movimentos internos do território devido à ausência da mobilidade necessária. 
Os dados das frequências de voos do aeroporto de Pelotas também foram coletados conforme Tabela 2.

TABELA 2 - OFERTA DE VOOS E DESTINOS (PELOTAS/RS)

\begin{tabular}{|c|c|c|c|c|c|c|c|}
\hline \multirow[b]{2}{*}{ Origem } & \multirow[b]{2}{*}{ Alcance $^{17}$} & \multirow[b]{2}{*}{$\begin{array}{c}\text { Companhia } \\
\text { aérea }\end{array}$} & \multicolumn{2}{|c|}{ Frequências } & \multirow[b]{2}{*}{$\begin{array}{c}\text { Média } \\
\text { Preço } \\
(\mathbf{R} \$)\end{array}$} & \multirow[b]{2}{*}{$\begin{array}{c}\text { Duração } \\
\text { a partir } \\
\text { de }(\mathbf{h})\end{array}$} & \multirow[b]{2}{*}{$\begin{array}{c}\text { Distância } \\
\text { Terrestre } \\
\quad(\mathbf{k m})\end{array}$} \\
\hline & & & $\begin{array}{l}\text { Média } \\
\text { Diária }\end{array}$ & $\begin{array}{c}\text { Voos } \\
\text { semanai } \\
\mathbf{S}\end{array}$ & & & \\
\hline Porto Alegre & $\mathrm{N}$ & Azul & 1,28 & 9 & 141,33 & $0: 55$ & 220 \\
\hline
\end{tabular}

FONTE: Elaboração própria dos autores (2015), com base em informações dos sites das companhias aéreas.

Verificou-se que Pelotas possuía uma única rota, que tinha como destino a capital Porto Alegre, sendo, portanto, a única interação espacial via transporte aéreo. Observou-se que, diferentemente do trecho Pelotas/Porto Alegre que possuía um voo diário, no final de semana havia dois voos a mais entre Porto Alegre e Pelotas, totalizando nove voos semanais durante o período pesquisado. Não foram coletados dados sobre o aeroporto de Rio Grande, também localizado zona sul do estado, pois o mesmo não possuía aéreo com linhas regulares.

No presente trabalho também buscou-se analisar a oferta de voos regulares do Uruguai, conforme Tabela 3.

TABELA 3 - OFERTA DE VOOS E DESTINOS (MONTEVIDÉU/URUGUAI)

\begin{tabular}{|c|c|c|c|c|c|c|c|}
\hline \multirow[b]{2}{*}{ Origem } & \multirow[b]{2}{*}{ Alcance } & \multirow[b]{2}{*}{$\begin{array}{c}\text { Companhia } \\
\text { aérea }\end{array}$} & \multicolumn{2}{|c|}{ Frequências } & \multirow{2}{*}{$\begin{array}{c}\text { Média } \\
\text { Preço } \\
(\mathbf{R} \$)\end{array}$} & \multirow{2}{*}{$\begin{array}{l}\text { Duração a } \\
\text { partir de } \\
\text { (h) }\end{array}$} & \multirow{2}{*}{$\begin{array}{l}\text { Distância } \\
\text { Terrestre } \\
\quad(\mathbf{k m})\end{array}$} \\
\hline & & & $\begin{array}{l}\text { Média } \\
\text { Diária }\end{array}$ & $\begin{array}{c}\text { Voos } \\
\text { semanais }\end{array}$ & & & \\
\hline Buenos Aires & I & $\begin{array}{l}\text { Aerolíneas } \\
\text { BQB }\end{array}$ & 5,85 & 41 & 467,51 & $0: 45$ & 280 \\
\hline São Paulo & I & $\begin{array}{l}\text { Gol } \\
\text { Tam }\end{array}$ & 5,42 & 38 & $1.869,63$ & $2: 45$ & 1565 \\
\hline Santiago & I & Lan & 2,71 & 19 & $1.896,58$ & $2: 20$ & 2111 \\
\hline Cidade do Panamá & I & Copa & 1,57 & 11 & $2.264,92$ & $7: 17$ & 5469 \\
\hline Rio de Janeiro & I & Tam & 1,14 & 8 & $1.529,95$ & $3: 15$ & 2365 \\
\hline Lima & I & Avianca & 1 & 7 & $2.388,89$ & $4: 35$ & 4651 \\
\hline Madri & I & Iberia & 1 & 7 & $2.102,42$ & $12: 40$ & 9958 \\
\hline Miami & I & $\begin{array}{l}\text { American } \\
\text { Airlines }\end{array}$ & 1 & 7 & $3.042,00$ & $9: 20$ & 7212 \\
\hline Paris & I & Air France & 1 & 7 & $10.497,00$ & $16: 05$ & 10973 \\
\hline
\end{tabular}

17 "N" refere-se a voo de alcance nacional e "I" refere-se a voo de alcance internacional. 


\begin{tabular}{l|c|c|c|c|c|c|r} 
& \multicolumn{1}{|c}{ Continuação... } \\
Assunção & I & BQB & 0,85 & 6 & $1.236,41$ & $2: 20$ & 1443 \\
Porto Alegre & I & Gol & 0,57 & 4 & $2.049,28$ & $1: 30$ & 713 \\
$\begin{array}{l}\text { Santa Cruz de La } \\
\text { Sierra }\end{array}$ & I & Amaszonas & 0,57 & 4 & $2.356,00$ & $3: 40$ & 2686 \\
\hline
\end{tabular}

FONTE: Elaboração própria dos autores (2015), com base em informações dos sites das companhias aéreas.

Pôde-se observar que o destino com maior densidade de tráfego com Montevidéu estava sendo Buenos Aires. A capital argentina, além de ser um centro de transferência de passageiros para a América do Sul, Europa e Estados Unidos, possui curta distância aérea com a capital uruguaia e oferece duas opções de aeroportos, Aeroparque e Ezeiza, a $8 \mathrm{~km}$ e $31 \mathrm{~km}$ do centro da cidade, respectivamente. $\mathrm{O}$ trajeto estava sendo comercializado pela companhia aérea argentina Aerolíneas Argentinas e a uruguaia BQB. Ressalta-se que o deslocamento entre as duas capitais também se fazia possível por meio da travessia fluvial do Rio da Prata, direto da capital uruguaia ou por Colônia do Sacramento, segundo informações de umas empresas que estavam operando essa rota, a Buquebus (2017).

Depois de Buenos Aires, as maiores frequências com chegada em Montevidéu tinham origem em São Paulo, proeminentemente assim como Porto Alegre. O trajeto com voos diretos estava sendo comercializado por duas empresas brasileiras, a Gol e a Tam.

A capital do Chile, Santiago, apresentou, por sua vez, a frequência de 19 voos semanais, sendo estes comercializados pela companhia aérea Lan-Tam. Em seguida se posicionou a cidade do Panamá, que apresentou 11 semanais, operados pela empresa Copa. Sendo assim, verificou-se a importância do hub dessa companhia para a cidade de Porto Alegre assim como para Montevidéu.

O Rio de Janeiro, por sua vez, possuía oito voos diretos por semana com destino a Montevidéu, operados pela Tam. Pôde-se observar que os preços eram inferiores aos operados a partir de São Paulo, apesar de a distância terrestre ser superior.

Lima, a capital do Peru, apareceu na sequência com sete voos semanais, assim como observado na Tabela 1. Com a mesma frequência semanal se posicionaram as cidades de: Madri, capital da Espanha, importante entrada na Europa e com idioma em comum; Miami, importante destino com opções de conexão com outras cidades dos Estados Unidos da América, e Paris, capital da França, cujas passagens apresentaram 
tarifas elevadas em razão do período de alta temporada. Verificou-se ainda que as rotas estavam sendo operadas por empresas aéreas estrangeiras.

A capital do Uruguai possuía, ainda, seis voos semanais com destino à capital paraguaia Assunção, e que eram operados pela companhia aérea uruguaia BQB. A mesma frequência apresentou Porto Alegre, que, apesar de possuir curta distância aérea estava operando poucos voos diretos. Conforme verificado, esses estavam sendo operados pela companhia Gol. Com a mesma frequência de voos se posicionou a cidade boliviana de Santa Cruz de La Sierra, operados pela companhia aérea Amaszonas.

Além disso, pôde-se observar que não havia quaisquer ligações aéreas entre Montevidéu e demais cidades uruguaias, o que poderia estar relacionado à pequena extensão territorial e, consequentemente, à facilitada interligação e mobilidade por meio de outros modos, em especial o rodoviário.

Verificou-se, ainda, que a companhia aérea BQB só estava operando dois destinos além de Montevidéu (Buenos Aires e Assunção), o que poderia de algum modo beneficiar companhias aéreas estrangeiras na operação das demais rotas.

Também se observou que o aeroporto de Montevidéu estava operando exclusivamente voos diretos, o que deveria ser uma condição relacionada à liberdade do $\operatorname{ar}^{18}$, ou seja, às rotas em que as companhias estrangeiras são autorizadas a prestar serviços, respeitando o território do Estado contratante.

\subsection{DIAGNÓSTICO DA ACESSIBILIDADE RODOVIÁRIA: TRANSPORTE COLETIVO}

Ainda na seção dos resultados, tendo apresentando o diagnóstico da oferta e de transporte aéreo de Porto Alegre, Montevidéu e Pelotas, passa-se à apresentação e discussão do diagnóstico da conectividade rodoviária (transporte coletivo) da área de fronteira em estudo, primeiramente com o Brasil, e, posteriormente, com o Uruguai.

\subsubsection{Conectividade da fronteira Chuí/Chuy com o Brasil}

O trajeto Pelotas a Chuí/Brasil estava possuindo o trecho operado pela empresa Embaixador. Constatou-se 5 saídas de coletivos diariamente com destino ao

\footnotetext{
${ }^{18}$ Direito de sobrevoar o território, fazer escala técnica, realizar transporte de passageiros e de cargas concedido em acordos bilaterais entre a companhia aérea e o Estado (PALHARES, 2002).
} 
Chuí/Brasil. O trajeto possuía $264 \mathrm{~km}$, tendo duração de aproximadamente 4 horas, ao custo de $\mathrm{R} \$ 50,80$ (com seguro) para o passageiro. A rota Rio Grande - Chuí/Brasil também estava sendo operada pela empresa Embaixador, com duas rotas diárias. O trajeto possuía $247 \mathrm{~km}, 3 \mathrm{~h} 40$ de duração, custando $\mathrm{R} \$ 46,50$ (com seguro) para o viajante.

O trajeto entre Porto Alegre e Chuí, por sua vez, estava sendo operado pela empresa Planalto. As saídas da capital aconteciam às 13h e $23 \mathrm{~h} 30$ (com exceção do sábado em que era oferecido o trajeto de 13h). O tempo de duração da viagem estava variando de acordo com o horário de saída. O trajeto com saída às $13 \mathrm{~h}$ tinha estimativa de duração de $8 \mathrm{~h} 30$, pois se previa uma parada ocasional para melhor alocação de passageiros e bagagens durante o percurso, incluindo a possibilidade de troca de veículo. A viagem com saída às $23 \mathrm{~h} 30$, por sua vez, possuía duração aproximada de $07 \mathrm{~h} 30^{19}$.

No caso dos trajetos de Porto Alegre a Chuí e Chuí a Porto Alegre, é importante destacar que, apesar de a empresa oferecer duas viagens, a mesma estava vendendo os bilhetes como comum e executivo para o horário de $13 \mathrm{~h}$, e semidireto e executivo no horário de 23h30. A diferença estava nos serviços adicionais oferecidos, como água, travesseiro, cobertor e poltrona com mais posições de inclinação e, consequentemente, no valor do bilhete. O valor com saída diurna era de $\mathrm{R} \$ 99,80$ com seguro, porém sem os serviços adicionais, e R\$ 150,80 com seguro e tendo incluso serviços extras. O horário com saída à noite, custava, por sua vez, R\$ 117,95 com seguro, porém, em poltrona comum. Ao contratar os serviços extras e o seguro o valor subia para $\mathrm{R} \$$ 151,25 .

É importante destacar que o seguro não era obrigatório. Porém, a diferença de serviços em uma mesma viagem poderia dificultar a compreensão dos clientes durante o processo de compra, principalmente ao diferenciar os serviços como "semidireto" e "executivo", ${ }^{20}$ Os termos poderiam levar a que clientes, principalmente não lusófonos, a

\footnotetext{
19 Outras paradas eram realizadas no trajeto Porto Alegre-Chuí: Em Cristal/RS, com intervalo para alimentação (em torno de 20 minutos), e em Pelotas/RS, para troca de motorista (10 minutos, aproximadamente).

${ }^{20}$ A informação foi encontrada no site da empresa que estava realizando o trajeto, a Planalto, por meio de site cujo endereço foi mencionado anteriormente.
} 
entenderem, equivocadamente, que se tratava de dois veículos diferentes, em que um realizava o percurso de maneira direta ao destino e o outro não.

\subsubsection{Conectividade da fronteira Chuí/Chuy com o Uruguai}

Seis empresas de transporte coletivo estavam tendo saídas de Montevidéu à cidade fronteiriça Chuy, sendo elas: TTL, Expreso Chago, Cot, Cynsa, Rutas del Sol e Ega. Somando a oferta de tais empresas ${ }^{21}$, verificou-se que eram oferecidas 94 viagens de segunda a sexta, 18 aos sábados e 17 aos domingos. Totalizavam-se assim 129 viagens por semana, tendo como média 18,43 por dia. O valor da viagem variava de 553 a 555 pesos, aproximadamente $\mathrm{R} \$ 56,06^{22}$.

Apenas uma empresa (Expreso Chago) realizava o itinerário através da Ruta 8 (via cidade de Lascano), as demais realizavam o trajeto através da Ruta 9. Conforme informações das empresas pesquisadas, a diferença de quilometragem não era significativa. O que variava, independentemente da rota, era o tempo de deslocamento. A variação ocorria conforme horários dos trajetos. Sendo assim, pôde-se verificar que, apesar do percurso não variar em quilometragem, poderia variar conforme tempo de deslocamento. Isso se devia, possivelmente, ao fato das empresas realizarem períodos de intervalos maiores nas paradas que realizavam nos trajetos e/ou maiores números de estações. De maneira geral, verificou-se que a oferta de viagens da fronteira às cidades uruguaias não sofria alterações significativas de categoria de serviços e de preço, apesar da variedade de empresas que operavam na região.

A empresa TTL realizava trajetos de Montevidéu até cidades brasileiras como Pelotas e Porto Alegre. Na região de fronteira a parada era realizada em Chuy/Uruguai. O mesmo ocorrendo no trajeto contrário, com saída de Porto Alegre, por exemplo. Dessa forma, o passageiro que precisasse ir à cidade de Chuí/Brasil, deveria desembarcar em Chuy/Uruguai e se deslocar até o outro lado da fronteira.

Verificou-se uma saída diária às $21 \mathrm{~h}$ de segunda a sábado em veículo convencional, e que às sextas-feiras havia um trajeto extra, em ônibus leito, às $21 \mathrm{~h} 15$. Não foram encontrados dados a respeito de valor, rota e tempo de duração do trajeto

\footnotetext{
${ }^{21}$ Não foram encontrados dados sobre a oferta de serviços da empresa Ega.

${ }^{22}$ Conforme cotação do dia $1^{\circ}$ de outubro de 2014, conferida no site www.financeone.com.br.
} 
Montevidéu/Chuy. Porém, pelo horário de saída do veículo da capital uruguaia, considerando o tempo de deslocamento até a fronteira, a parada para embarque e desembarque na cidade de Chuy estava ocorrendo de madrugada.

A outra empresa que estava realizando o trajeto entre fronteiras era a EGA. Porém, não foram encontrados dados das operações e possibilidade de simulação de compra na página web da mesma.

É importante destacar que diferentemente dos passageiros que embarcavam do "lado" uruguaio, os que embarcavam do "lado" brasileiro ficavam impossibilitados de escolher entre duas ou mais empresas. Dessa forma, ao consumidor não estavam sendo oferecidas opções em termos de horários, preços e serviços que melhor atendessem às suas necessidades. O seguro também é um aspecto que poderia confundir os passageiros no Brasil, pois as garantias e benefícios não eram apresentados aos consumidores.

Além disso, foi possível verificar que o deslocamento até a fronteira era dificultado, tanto do ponto de vista da falta de opções em termos de modais (o modal disponível é o rodoviário), quanto da fraca intermodalidade existente.

\section{CONSIDERAÇÕES FINAIS}

Retomando-se o objetivo deste trabalho, que era o de diagnosticar a acessibilidade geográfica da fronteira Chuí/Brasil - Chuy/Uruguai, considera-se que este foi atingido por meio da análise dos principais fluxos do transporte aéreo dos aeroportos de Pelotas/RS, Porto Alegre/RS e Montevidéu/Uruguai, os mais próximos à área da fronteira Chuí-Chuy e que estavam oferecendo linhas aéreas regularmente no período de coleta de dados. Paralelamente a isso, pôde-se realizar o levantamento da oferta de linhas de transporte coletivo rodoviário, partindo do Brasil e do Uruguai em direção a essa área de fronteira.

Justifica-se o atingimento do objetivo, dentro dos recortes pré-estabelecidos, por meio de dados que apontaram determinadas densidades e algumas rarefações em termos de ligações aéreas e rodoviárias. Além disso, em se tratando de uma área de fronteira, os dados apontaram tanto para determinadas descontinuidades, quanto para algumas complementaridades. No transporte coletivo observaram-se a um só tempo 
descontinuidades nas linhas de transporte rodoviário; por outro lado, visualizaram-se algumas complementaridades na cobertura da área de fronteira entre os serviços dos aeroportos brasileiros e os uruguaios estudados, a depender da origem. Atendo-se, porém, à oferta dos voos entre os três aeroportos pesquisados, destacar-se-ia a baixa conectividade entre os aeroportos brasileiros de Porto Alegre e Pelotas com o de Montevidéu.

Ao problematizar os efeitos da oferta de transporte aéreo e rodoviário (coletivo) diagnosticada sobre a acessibilidade geográfica até as fronteiras, como Chuí/Brasil e Chuy/Uruguai buscou-se documentar a (i)mobilidade turística, transcendendo a temática dos transportes, pois reconheceu-se os demais fatores como motivadores ou restritivos da mobilidade dos fluxos e acessibilidade geográfica aérea.

A partir do presente estudo foi possível verificar que, para compreender a mobilidade, se faz necessário considerar elementos políticos e econômicos, manifestados pela estruturação das redes técnicas e, consequentemente, do próprio território. Também foi possível observar que o fenômeno de centralização das operações estava promovendo a centralidade de algumas cidades em processo de desenvolvimento da inserção na globalização.

Sugere-se mapear de forma mais exaustiva as informações, incluindo os voos com escala, tendo em conta diferentes épocas do ano para verificar se ocorre variação. Além disso, sugere-se considerar também a acessibilidade local e/ou micro acessibilidade, que, conforme foi diagnosticada, interfere na dinâmica intra-urbana no turismo emissivo e receptivo nas áreas de fronteira, resguardando as especificidades de cada uma das acessibilidades macro e micro.

Estudos dessa natureza permitem não só analisar, mas até mesmo documentar a oferta de serviços de aéreo sazonais e dessa forma conhecer as flutuações que ocorrem nesse setor. Os estudos podem trazer contribuições gerenciais para o planejamento e gestão dos destinos em questão em menor medida a área de fronteira, já que a acessibilidade é um componente indissociável da competitividade sustentável das destinações turísticas. 


\section{REFERÊNCIAS}

AEROPUERTO de Carrasco. Disponível em: <http://www.aeropuertodecarrasco.com.uy/>. Acesso em: 21/01/2015.

ALLIS, T. Experiência de mobilidade turística no espaço público urbano. In: PANOSSO NETTO, A.; GAETA, C. (Org.). Turismo de Experiência. 1. ed. São Paulo: Senac SP, 2010, p. 300-320.

ALliS, T., PAUlA, A. T. de; RASZL, V. Turismo de Compras nas Fronteiras Brasileiras: Panorama geral e perspectiva à luz das políticas vigente. In: PIERI, V. S. G. de; TELES, R. M. de S. (Org.). Turismo e relações internacionais: fronteiras transnacionais, paradiplomacia das cidades e inserção internacional do Brasil. Rio de Janeiro: Cenegri, 2015, p. 83-110.

BARAT, J. Projeto Perspectiva do Desenvolvimento Brasileiro Livro Eixo de Infraestrutura Econômica: Panorama e Perspectivas para o Transporte Aéreo no Brasil e no Mundo. Brasília: Ipea, 2010. 36 slides, color. Disponível em: <www.ipea.gov.br/.../100531_comunicaipea_54_apresentacao02.pdf>. Acesso em: $10 / 04 / 2015$.

BECKER, B. Geopolítica na virada do milênio: logística e desenvolvimento sustentável. In: GOMES, P. C. C.; CORREAA, R. L.; CASTRO, I. E. (Org.). Geografia: conceitos e temas. 8. ed. Rio de Janeiro: Betrand Brasil, 2006, p. 271-307.

BENI, M. C. Análise estrutural do turismo. 12. ed. São Paulo: Senac SP, 2007.

Globalização do Turismo. 3. ed. São Paulo: Aleph, 2011.

BENTO, F. R. Fronteiras, significado e valor - a partir da experiência das cidades gêmeas de Rivera e Santana do Livramento. Conjuntura Austral, v. 12, n. 3, p. 44-60, jun. 2012.

BUQUEBUS. Destinos. Buquebus: Buenos Aires, 2017. Disponível em: <https://www.buquebus.com/portugues $>$. Acesso em: 06/03/2017.

CASTIllo, M.; MONTEVERDE, A. Pluna como empresa mixta: Viabilidad y perspectivas. 2011. 249 f. Monografia (Especialização) - Curso de Contador Público, Universidad de La República, Montevideu, 2011. Disponível em: <https://www.colibri.udelar. edu.uy/bitstream/123456789/417/1/M-CD4318.pdf>. Acesso em: 10/05/2015.

CASTELlS, M. A era da informação: economia, sociedade e cultura. A sociedade em rede. 1 v. 2. ed. São Paulo: Paz e Terra, 1999. 
CASTRO, R.; LOHMANN, G. Transporte Aéreo e Turismo. In: LOHMANN, G.; FRAGA, C.; CASTRO, R. (Org.). Transportes e destinos turísticos: planejamento e gestão. Rio de Janeiro: Elsevier, 2013, p. 115-142.

CASTROGIOVANNI, A. C. Paisagens sem fronteiras: geograficidade sem limites. In: BENI, M. C. (Org.). Turismo: planejamento estratégico e capacidade de gestão desenvolvimento regional, redes de produção e clusters. Barueri: Manole, 2012, p. 2944.

COHEN, E.; COHEN, S. Current sociological issues and theories in tourism. Annals of Tourism Research, v. 39, n. 4, p. 2177-2202, out. 2012.

COCCO, R. G. Verbetes. In: SILVEIRA, M. R. (Org.). Circulação, Transportes e Logística: diferentes perspectivas. São Paulo: Outras Expressões, 2011, p. 613-614.

COPA AIRLINES. Centro de conexões das Américas. Panamá: Copa, 2017. Disponível em: <https://www.copaair.com/pt/web/br>. Acesso em: 06/03/2017.

CORIOLANO, L. N.; FERNANDES, L. M. Migração temporária e mobilidade sazonal no turismo. In: SEMINÁRIO DE PESQUISA E PÓS-GRADUAÇÃO EM TURISMO, 9., 2012, São Paulo. Anais... São Paulo: Aleph, 2012.

EMPRESA Brasileira de Infraestrutura Aeroportuária - Infraero. Disponível em: <http://www4.infraero.gov.br>. Acesso em 20/01/2015.

FUNDAÇÃO Instituto de Pesquisas Econômicas - Fipe. Demanda Turística Internacional. Disponível em: <http://www.dadosefatos.turismo.gov.br/dadosefatos/demanda_turistica/interna cional>. Acesso em: 17/08/2015.

Caracterização e dimensionamento do turismo doméstico no Brasil 2010/2011. Disponível em: <http://www.dadosefatos.turismo.gov.br/2016-02-04-11-5403/demanda-tur\%C3\%ADstica-nacional/item/download/444_c3973dd978715416c87 16edabb0769a1.html>. Acesso em: 07/02/2017.

FLORES, H. A. H. Turismo no Rio Grande do Sul: 50 anos de pioneirismo no Brasil. Porto Alegre: Edipucs, 1993.

GASTAL, S. de A. Correio Aéreo e aviação civil: Os primeiros passos da Varig. Turismo \& Sociedade, Curitiba, v. 2, n. 2, p. 185-211, out. 2009.

HELMS, H. A aviação comercial e a quebra da Varig. Aviation In Focus, Porto Alegre, v. 1 , n. 1, p. 36-47, ago. 2010. Disponível em: <repositorio.pucrs.br/dspace/handle/10923/3818 ?locale=pt_BR>. Acesso em: $10 / 04 / 2015$.

HISSA, C. E. V. A mobilidade das fronteiras: inserções da geografia na crise da modernidade. Belo Horizonte: EdUFMG, 2002. 
INSTITUTO Brasileiro de Geografia e Estatística - IBGE. Chuí. Disponível em: $<$ http://www.cidades.ibge.gov.br/painel/painel.php?lang=\&codmun=430543\&search=ri o-grande-do-sul|chui|infograficos:-dados-gerais-do-municipio>. Acesso em: $15 / 10 / 2014$.

INSTITUTO de Estudos Avançados da Universidade De São Paulo - IEA. Ranking das cidades globais. São Paulo: IEA, 2016. Disponível em: <http://www.iea.usp.br/imagens/cidades-globais-1/view>. Acesso em: 06/03/2017.

KUNZ, J. G. A Estruturação da Rede Técnica de Transporte Aéreo, as Funções Nodais dos Aeroportos e o Turismo. Geografia em Atos, Presidente Prudente, v. 1, n. 14, p. 17-35, jan. 2014. Disponível em: <http://revista.fct.unesp.br/index.php/geografiaematos/ article/viewFile/2041/pdfjk>. Acesso em: 15/04/2015.

LIPOVICH, G. A. Las Concentraciones Territoriales de los flujos Aerocomercial como consequencia de la Centralización del Mercado Aéreo en el contexto de la integración Regional en el Mercosur. Revista do Departamento de Geografia da USP, São Paulo, v. 18, p. 75-88, out. 2006. Disponível em: <http://www.revistas.usp.br/rdg/article/view/47267/51003>. Acesso em: 15/04/2015.

MARURI, J. Conmemorando la tentativa exitosa: un siglo de aviación civil en Uruguay. 2010. Disponível em: <http://www.espectador.com/sociedad/190815/ conmemorando-la-tentativa-exitosa-un-siglo-de-aviacion-civil-en-uruguay>. Acesso em: 30/03/2015.

OSÓRIO, L. M. Limites, fronteiras, redes. In: STROHAECKER, T. M., et al. (Org.). Fronteiras e espaço global. Santana do Livramento: AGB, p. 41-50, 1998.

PALHARES, G. L. Transportes turísticos. São Paulo: Aleph, 2002.

PEREIRA, A. P. C. A incógnita da concorrência no mercado de transporte aéreo brasileiro. In: ENCONTRO NACIONAL DA ASSOCIAÇÃO DE PÓS-GRADUAÇÃO E PESQUISA EM GEOGRAFIA (ENANPEGE), 9., 2011, Goiânia. Anais... Goiânia: ENANPEGE, 2011.

Asas da centralidade em céus conhecidos: a dinâmica empresarial do setor de transporte aéreo no território brasileiro. 374 p. Tese (Doutorado em Geografia) Departamento de Geografia, Universidade de São Paulo, São Paulo, 2014.

PEREIRA, A. P. C.; SILVEIRA, M. Integração territorial, interações espaciais e desenvolvimento regional: aportes para a discussão sobre o setor aéreo. In: ENCONTRO DE GEÓGRAFOS DA AMÉRICA LATINA (EGAL), 12., 2009, Montevidéu. Anais... Montevidéu: EGAL, 2009.

RAFFESTIN, C. Por uma geografia do poder. São Paulo: Ática, 1993. 
SANTOS, M.; SILVEIRA, M. L. O Brasil: território e sociedade no início do século XXI. 6. ed. Rio de Janeiro: Record, 2004.

SILVEIRA, R. da. Redes e território: uma breve contribuição geográfica ao debate sobre a relação sociedade e tecnologia. Biblio 3 W - Revista Bibliográfica de Geografía y Ciencias Sociales, v. 8, n. 451, 2003.

TAP. Sobre a TAP. Lisboa: TAP, 2017. Disponível em: <http://www.tapportugal.com/Info/pt/sobre-tap/companhia/valores-missao>. Acesso em: 06/06/2017.

URUGUAY. Instituto Nacional de Estadística. Departamento: Rocha. 2014. Disponível em: <http://www.ine.gub.uy/censos2011/resultadosfinales/rocha.html>. Acesso em: 06/06/2016.

Recebido em: 27-09-2016.

Aprovado em: 27-10-2016.

Versão Final publicada em: 12-03-2017. 